\title{
Superconductivty and magnetic properties of $\left(\mathrm{Ru}_{1-\mathrm{x}} \mathrm{Nb}_{\mathrm{x}}\right) \mathrm{Sr}_{2}\left(\mathrm{Sm}_{1.4} \mathrm{Ce}_{0.6}\right) \mathrm{Cu}_{2} \mathrm{O}_{\mathrm{z}}$
}

\author{
H. K. Lee*, S.M. Bae, and J.M.Lee
}

Kangwon National University, Chuncheon, Korea)

(Received 16 July 2013; revised or reviewed 2 September 2013; accepted 3 September 2013)

\begin{abstract}
We investigated the effect of $\mathrm{Nb}$ substitution for $\mathrm{Ru}$ on the structural and magnetic properties of $\left(\mathrm{Ru}_{1-\mathrm{x}} \mathrm{Nb}_{\mathrm{x}}\right) \mathrm{Sr}_{2}\left(\mathrm{Sm}_{1.4} \mathrm{Ce}_{0.6}\right) \mathrm{Cu}_{2} \mathrm{O}_{z}$ Samples. X-ray diffraction measurements indicated that nearly single-phase samples are formed in the range from $\mathrm{x}=0$ to 1.0 . The superconducting transition temperature determined from the inflection in the field-cooled magnetic susceptibility decreased only slightly from $T_{c}=25 \mathrm{~K}$ for $\mathrm{x}=0$ to $\mathrm{T}_{\mathrm{c}}=22 \mathrm{~K}$ for $\mathrm{x}=1.0$, in consistent with the change in room temperature thermopower of the samples. However, the $\mathrm{Nb}$ substitution for $\mathrm{Ru}$ above $\mathrm{x}=0.25$ significantly suppressed the weak ferromagnetic component of the field-cooled magnetic susceptibility. It was also found that the $\mathrm{Nb}$ substitution for $\mathrm{Ru}$ results in an enhanced diamagnetic susceptibility with $\mathrm{Nb}$ content above $\mathrm{x}=0.5$ in both zero field-cooled and field-cooled magnetization measurements, in contrast to the behavior of the samples with $\mathrm{x} \leq 0.5$ in which the diamagnetic susceptibility decreases as the $\mathrm{Nb}$ content increases.
\end{abstract}

Keywords : $\mathrm{Nb}$ substitution, $\mathrm{Ru}, \mathrm{Sr}_{2}(\mathrm{Sm}, \mathrm{Ce})_{2} \mathrm{Cu}_{2} \mathrm{O}_{z}$, superconductivity, magnetic property

\section{I. 서 론}

초전도 특성과 강자성 특성은 상호 배타적인 특성으 로 인해 공존하기 어려운 것으로 알려져 왔다[1]. 그 러나 $\mathrm{RuSr}_{2}\left(\mathrm{R}_{2-\mathrm{y}} \mathrm{Ce}_{\mathrm{y}}\right) \mathrm{Cu}_{2} \mathrm{O}_{10}$ 계[2] 및 $\mathrm{RuSr}_{2} \mathrm{GdCu}_{2} \mathrm{O}_{8}$ 계 [3] 에서 임계온도 $\left(\mathrm{T}_{\mathrm{c}}\right)$ 가 약 $50 \mathrm{~K}$ 이하인 초전도 특 성과 자기전이온도 $\left(T_{m}\right)$ 가 $100 \sim 180 \mathrm{~K}$ 인 약한 강자 성 특성이 공존함이 보고된 후 이들 배타적인 두 특성 이 공존하는 메커니즘을 이해하기 위해 $\mathrm{Ru}$ 계 자성 초 전도체에 대한 많은 연구가 수행되어 오고 있다. 이들 자성 초전도체의 구성은 일반적으로 $\mathrm{RuSr}_{2}\left(\mathrm{R}_{2-\mathrm{y}} \mathrm{Ce}_{\mathrm{y}}\right) \mathrm{Cu}_{2} \mathrm{O}_{10}(\mathrm{Ru}-1222)$ 및 $\mathrm{RuSr}_{2} \mathrm{RCu}_{2} \mathrm{O}_{10}(\mathrm{Ru}-1212)$ 로 나타낼 수 있으며, $\mathrm{R}$ 은 희토류 원소로서 $\mathrm{Sm}, \mathrm{Eu}$ 및 $\mathrm{Gd}$ 의 경우만 상압에서 단 일상이 형성됨이 알려져 왔다[4]. 특히 $\mathrm{Ru}-1222$ 계는 $\mathrm{Ru}-1212$ 계에 비해 강자성 특성이 크게 관측되어[5] 그 원인을 파악하기 위해 많은 치환연구가 수행되어 왔 으며, $\quad\left(\mathrm{Ru}_{1}-{ }_{\mathrm{x}} \mathrm{M}_{\mathrm{x}}\right) \mathrm{Sr}_{2}\left(\mathrm{R}_{2-\mathrm{y}} \mathrm{Ce}_{\mathrm{y}}\right) \mathrm{Cu}_{2} \mathrm{O}_{10}((\mathrm{Ru}, \mathrm{M})-1222)$ 조성에 대한 연구에서 $\mathrm{M}=\mathrm{Fe}[6], \mathrm{Co}[7], \mathrm{Nb}[8,9]$, $\mathrm{Mo}[10], \mathrm{Sn}[11], \mathrm{Sb}[12]$ 등의 원소 치환연구가 수행 되었다. 이들 원소 치환연구 결과, 치환량이 증가되면 약한 강자성 모멘트 및 자기전이온도가 급격히 감소하 는 특성이 관측됨으로써, 이 계에서 관측되는 약한 강 자성 모멘트는 $\mathrm{RuO}_{2}$ 층에 기인함이 밝혀졌다. 그러나 원소 치환에 따른 임계온도의 변화는 원소에 따라 다르 게 보고되고 있다. 가령, $\mathrm{Co}$ 치환의 경우 $\mathrm{x}=0.1$ 이상 치환하면 초전도 특성이 관측되지 않으며, $\mathrm{Sb}$ 치환의 경우 $\mathrm{x}=0$ 일 때 $43 \mathrm{~K}$ 에서 $\mathrm{x}=0.06$ 일 때 $20 \mathrm{~K}$ 로 감소함이 알려져 있다. 한편 $\mathrm{Mo}$ 치환의 경우는 $\mathrm{x}=$ $0,0.2,0.4$ 및 0.6 의 경우 각각 $33 \mathrm{~K}, 37.5 \mathrm{~K}, 40 \mathrm{~K}$ 및 $23 \mathrm{~K}$ 의 초전도 특성을 보이며 $\mathrm{x}=0.8$ 이상에서는 초 전도 특성이 관측되지 않음이 보고되어 있다. 한편 $\mathrm{Nb}$ 치환의 경우는 $\mathrm{x}=0.5$ 까지 치환하는 동안 임계온도

\footnotetext{
*Corresponding author: hklee221@kangwon.ac.kr
}

는 치환하지 않은 경우와 비교하여 약 $1-3 \mathrm{~K}$ 이내의 적은 감소가 관측됨이 보고되어 있다. 그러므로 $\mathrm{Nb}$ 을 $\mathrm{Ru}$ 대신 $100 \%$ 까지 치환했을 때의 특성을 연구하는 것은 흥미있는 일이다. 실제 $\left(\mathrm{Ru}_{\mathrm{x}} \mathrm{Nb}_{1-\mathrm{x}}\right) \mathrm{Sr}_{2}\left(\mathrm{Sm}_{1.2} \mathrm{Ce}_{0.8}\right) \mathrm{Cu}_{2} \mathrm{O}_{z}$ [13] 및 $\left(\mathrm{Ru}_{1-\mathrm{x}} \mathrm{Nb}_{\mathrm{x}}\right) \mathrm{Sr}_{2}\left(\mathrm{Sm}_{1.4} \mathrm{Ce}_{0.6}\right) \mathrm{Cu}_{2} \mathrm{O}_{z}[14]$ 조성으로 고압 의 산소 분위기로 열처리하여 $\mathrm{Nb}$ 를 $100 \%$ 까지 치환 한 시도가 있었다. 본 연구에서는 상압에서 $\left(\mathrm{Ru}_{1-\mathrm{x}} \mathrm{Nb}_{\mathrm{x}}\right) \mathrm{Sr}_{2}\left(\mathrm{Sm}_{1.4} \mathrm{Ce}_{0.6}\right) \mathrm{Cu}_{2} \mathrm{O}_{z}$ 조성의 시편을 합성 하고 $\mathrm{Nb}$ 치환에 따른 구조 및 자기적 특성을 체계적으 로 조사했다.

\section{II. 실험방법}

시편은 $99.9 \%$ 이상의 고순도 $\mathrm{RuO}_{2}, \mathrm{Nb}_{2} \mathrm{O}_{5}, \mathrm{SrCO}_{3}$, $\mathrm{Sm}_{2} \mathrm{O}_{3}, \mathrm{CeO}_{2}$ 및 $\mathrm{CuO}$ 분말을 이용해 고상반응법으로 $\left(\mathrm{Ru}_{1-\mathrm{x}} \mathrm{Nb}_{\mathrm{x}}\right) \mathrm{Sr}_{2}\left(\mathrm{Sm}_{1.4} \mathrm{Ce}_{0.6}\right) \mathrm{Cu}_{2} \mathrm{O}_{z} \quad(\mathrm{x}=0$, $0.25,0.5,0.75,1.0)$ 의 명목구성의 시편을 합성했다. 먼 저 혼합된 분말을 마노유발을 이용하여 잘 갈고 $960{ }^{\circ} \mathrm{C}$ 에서 공기중에서 10 시간 열처리한 후 $1010{ }^{\circ} \mathrm{C}$ 에서 질소 분위기로 10 시간 열처리했다. 그 후 시편 을 다시 갈고 페럿 형태로 만든 후 산소분위기에서 $1070{ }^{\circ} \mathrm{C} 20$ 시간, $1090{ }^{\circ} \mathrm{C} 40$ 시간 열처리했으며, $1090{ }^{\circ} \mathrm{C}$ 열처리 후 서냉과정 중 $400{ }^{\circ} \mathrm{C}$ 에와 $200{ }^{\circ} \mathrm{C}$ 에 서 각각 5 시간 씩 열처리 후 상온으로 온도를 내렸다. 고온의 열처리 과정 중 각 온도에서의 열처리 전 시편 은 매번 다시 갈고 패럿 형태로 성형했다.

시편의 상 형성 및 구조는 $\mathrm{X}$-선 회절 장치 $(\mathrm{CuK \alpha}$ 선 이용)를 이용했다. 상온의 열기전력은 미분 방법 [15]으로 측정했으며, 자기 감수율 측정은 Superconducting Quantum Interference Device (SQUID) 장치로 측정했다. 자기적 측정은 두 
가지 측정법으로 수행되었으며, zero-field-cooled $(\mathrm{ZFC})$ 측정에서는 자기장을 가하지 않은 상태에서 먼저 온도를 약 $4 \mathrm{~K}$ 로 낮춘 후 자기장을 가하여 온도를 올리며 측정되었으며, field-cooled (FC) 측정에서는 상온에서 먼저 자기장을 가한 상태로 온도를 낮춘 후 다시 온도를 올리며 측정했다. 이 때 가해진 자기장은 $20 \mathrm{Oe}$ 였다.

\section{III. 실험결과 및 논의}

Fig. 1은 $\left(\mathrm{Ru}_{1-\mathrm{x}} \mathrm{Nb}_{\mathrm{x}}\right) \mathrm{Sr}_{2}\left(\mathrm{Sm}_{1.4} \mathrm{Ce}_{0.6}\right) \mathrm{Cu}_{2} \mathrm{O}_{\mathrm{z}}(\mathrm{x}=0$, $0.25,0.5,0.75,1.0)$ 구성시편의 $\mathrm{X}$-선 회절 분석 결과를 보여준다. 시편의 $\mathrm{X}$-선 회절 피이크는 정방(tetragonal)구조의 밀러지수로 매김할 수 있었으며, $\mathrm{Nb}$ 을 치환한 $\mathrm{X}$-선 회절 양상은 $\mathrm{Nb}$ 을 치환하지 않은 시편의 경우와 거의 유사하게 단일상의 특성을 보여주며, $\left(\mathrm{Ru}_{1-\mathrm{x}} \mathrm{Nb}_{\mathrm{x}}\right) \mathrm{Sr}_{2}\left(\mathrm{Eu}_{1.5} \mathrm{Ce}_{0.5}\right) \mathrm{Cu}_{2} \mathrm{O}_{z}$ 계 [8] 의 경우처럼 $\mathrm{Nb}$ 치환으로 상의 순도가 향상됨을 보여주었다. 최소자승법으로 계산된 격자 상수는 $\mathrm{x}=0$ 의 경우 $a$ $=3,840 \AA, c=28.48 \AA$ 이었으며, $\mathrm{x}=1.0$ 의 경우 $a$ $=3,866 \AA, c=28.70 \AA$ 으로 $\mathrm{Nb}$ 치환량에 따라 거의 선형적으로 증가했다. 이 결과는 $\mathrm{Nb}^{+5}$ 의 이온반지름[16] (0.64 $\AA, \mathrm{CN}=6)$ 이 $\mathrm{Ru}^{+5}$ 의 이온반지름 $(0.565 \AA, \mathrm{CN}=6)$ 보다 크고 $\mathrm{Nb}$ 이 $\mathrm{Ru}$ 자리에 치환되는 것으로 설명된다.

Fig. 2의 결과는 $\left(\mathrm{Ru}_{1-x} \mathrm{Nb}_{\mathrm{x}}\right) \mathrm{Sr}_{2}\left(\mathrm{Sm}_{1.4} \mathrm{Ce}_{0.6}\right) \mathrm{Cu}_{2} \mathrm{O}_{z}$ $(\mathrm{x}=0,0.25,0.5,0.75,1.0)$ 시편들의 $\mathrm{ZFC}$ 및 $\mathrm{FC}$ 자화율 특성을 보여준다. $\mathrm{x}=0$ 인 시편의 경우 $\mathrm{ZFC}$ 측정결과와 $\mathrm{FC}$ 측정결과 간에 자기이력 특성을 보여주며, $\mathrm{FC}$ 측정은 저온에서 약한 강자성과 같은 자기모멘트가 존재함을 보여준다. 이 모멘트가 급격히 증가하는 온도를 보통 자기전이온도로 간주한다. 그러므로 Fig. 2의 결과는 $\mathrm{Nb}$ 의 치환량이 증가되면 강자성 모멘트의 크기가 감소하며, 자기전이온도도 감소함을 내는데, 이는 $\mathrm{Ru}$ 자리에 다른 원소를 치환한 후 시편의 자화율을 측정한 대부분의 연구 [6]-[12] 에서 관측되어온 실험결과와 일치한다.

본 연구의 흥미있는 한 결과는 $\mathrm{x}=0.5$ 이상의 경우 $\mathrm{FC}$ 측정에서 반자성을 보이는 마이스너(Meissner) 상태가 관측되며, 이 반자성의 크기가 $\mathrm{Nb}$ 치환량이 증가될수록 증가된다는 점이다. 또한 이 때 $\mathrm{ZFC}$ 측정으로 관측되는 반자성의 크기도 증가됨을 보여 주는데 이는 $\mathrm{x}$ 가 0.5 이하일 때 $\mathrm{Nb}$ 치환량이 증가함에 따라 $\mathrm{ZFC}$ 측정으로 관측되는 반자성의 크기는 감소하는 것과 대비된다. 또한 Fig. 2 의 결과에서 $\mathrm{x}=$ 0.5 이상의 시편에서 명백히 볼 수 있는 바와 같이 $\mathrm{ZFC}$ 측정에서 반자성을 보이는 초전도 전이온도는 $\mathrm{FC}$ 측정에서 자화률 곡선의 기울기가 급격히 변화되는 변곡점의 온도와 일치한다, 이 변곡점은 $\mathrm{Nb}$ 의 치환량이 적을 때도 화살표로 나타낸 바와 같이 계속 관측된다. $\mathrm{FC}$ 측정의 경우 자화도는 크게 (1)초전도 특성에 의한 반자성 모멘트, (2)희토류원소나 구리에 의한 상자성 모멘트, 그리고(3)Ru에 기인하는 약한 강자성 모멘트에 의해 결정된다고 볼 때 특정온도에서 시편이 초전도체가 되면 초전도체의 반자성 특성에 의해 $\mathrm{FC}$ 측정의 자화도가 감소될 수 있고 강자성 모멘트가 매우 크지 않을 경우 $\mathrm{FC}$ 측정에서 감소를

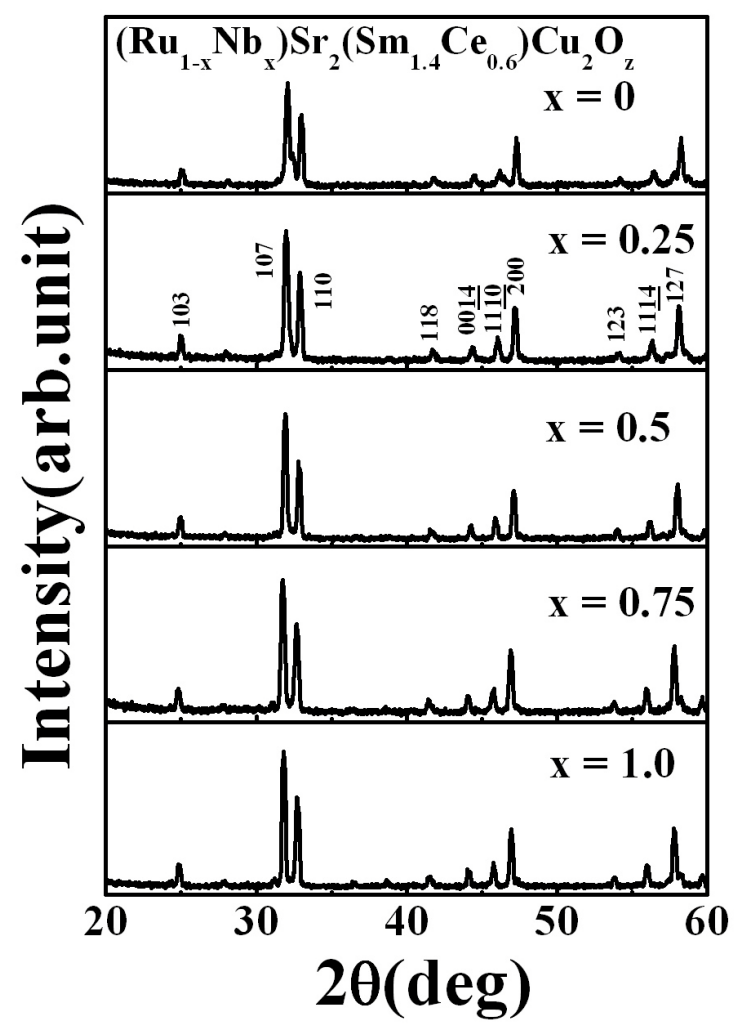

Fig. 1. Powder XRD patterns for $\left(\mathrm{Ru}_{1-\mathrm{x}} \mathrm{Nb}_{\mathrm{x}}\right) \mathrm{Sr}_{2}\left(\mathrm{Sm}_{1.4} \mathrm{Ceb}_{0.6}\right) \mathrm{Cu}_{2} \mathrm{O}_{\mathrm{z}}$ samples.

보이는 굴곡 또는 변곡으로 관측될 수 있으며, 이 변곡점은 초전도 전이온도로 간주될 수 있다[6],[10]. $\mathrm{FC}$ 측정으로 관측된 변곡점의 온도는 $\mathrm{x}=0$ 인 경우 $25 \mathrm{~K}$ 에서 $\mathrm{x}=1.0$ 일 때 $22 \mathrm{~K}$ 로 분석되었으며 이는 측정온도 간격인 $3 \mathrm{~K}$ 이내이다. 이 결과는 Watanabe 등 [14]에 의해 고압으로 합성된 $\left(\mathrm{Ru}_{1-\mathrm{x}} \mathrm{Nb}_{\mathrm{x}}\right) \mathrm{Sr}_{2}\left(\mathrm{Sm}_{1.4} \mathrm{Ce}_{0.6}\right) \mathrm{Cu}_{2} \mathrm{O}_{10}$ 계의 경우에도 $\mathrm{Nb}$ 치환에 따른 임계온도의 변화가 매우 적다는 결과와 일치하며, 합성 방법의 차이와 무관하게 $\mathrm{Nb}$ 치환의 고유 특성으로 볼 수 있다. 본 연구의 결과는 또한 $\mathrm{x}=$ 1.0 인 경우도 초전도 특성이 관측되었는데 이는 Ono[13]에 의해 연구된 $\mathrm{NbSr}_{2}\left(\mathrm{Sm}_{1.2} \mathrm{Ce}_{0.8}\right) \mathrm{Cu}_{2} \mathrm{O}_{z}$ 의 조성의 경우 초전도 특성이 관측되지 않은 것과 대비되며, 시편의 조성이 다른 것과도 연관되는 것으로 보인다.

한편, $\mathrm{x}=0,0.25,0.5,0.75$ 및 1.0 인 시편들의 상온 열기전력은 각각 $35.4,38.4,46.0,51.2$ 및 57.2 $\mu \mathrm{V}$ 였다. $\mathrm{P}$ 형 구리 산화물의 경우 임계온도 $T_{c}$ 와 $\mathrm{CuO}_{2}$ 구리평면당의 홀 농도 $(p)$ 사이에 경험적으로 역 이차함수의 관계가 있음이 밝혀져 있으며, 이 관계는 대부분의 구리 산화물에서 적용됨도 알려져 있다. 이 때 홀 농도와 $\mu \mathrm{V}$ 단위로 표시되는 상온 열기전력 $(S)$ 사이에 강한 상관관계가 있음이 알려져 있다. 즉 각 구리 산화물 계에서 최적 임계온도일 경우 약 $2 \mu \mathrm{V}$ 의 열기전력이 관측되며, 최적임계온도 보다 낮을 때는 홀 농도가 최적 상태보다 낮은 상태 (underdoped state)이거나 높은 상태(overdoped state)에 해당된다. 홀 농도가 최적상태에 비해 감소할 경우 열기전력은 양의 값으로 증가하며, 반대로 홀 농도가 과잉 상태로 증가할 경우는 열기전력이 음의 값으로 감소하며, 각 


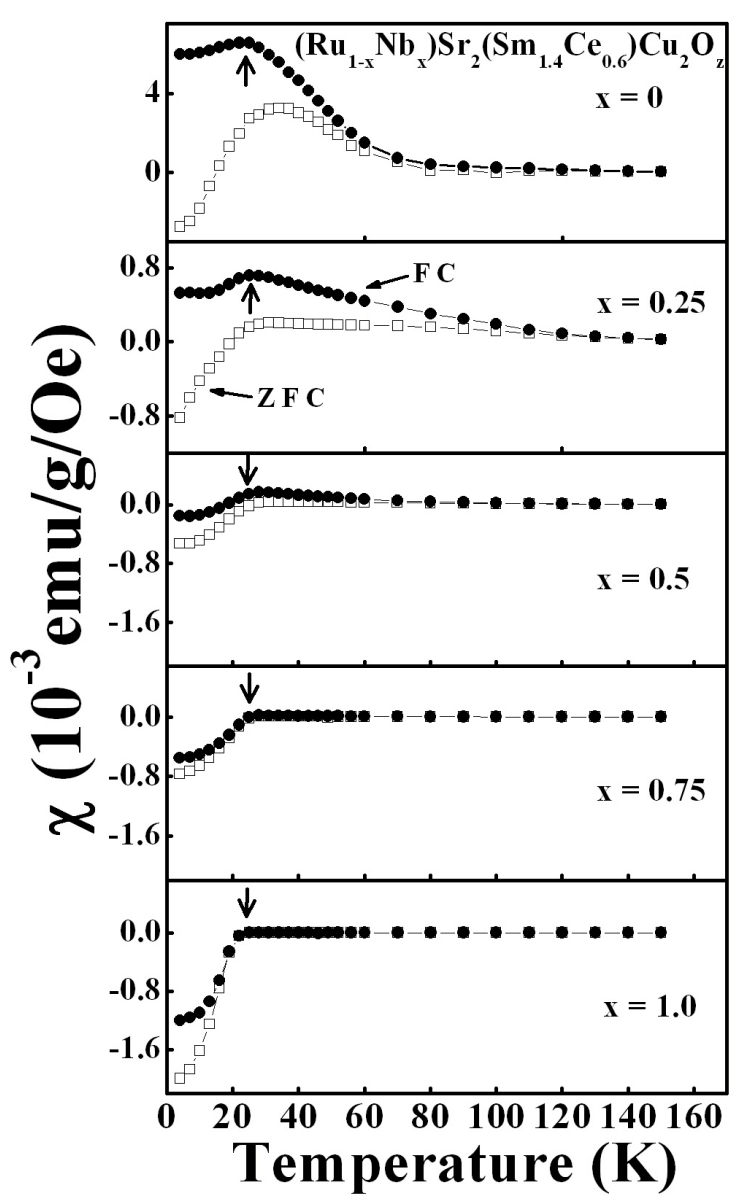

Fig. 2. The zero-field-cooled (ZFC) and field-cooled (FC) $\mathrm{dc}$ magnetization curves of $\left(\mathrm{Ru}_{1-\mathrm{x}} \mathrm{Nb}_{\mathrm{x}}\right) \mathrm{Sr}_{2}\left(\mathrm{Sm}_{1.4} \mathrm{Ceb}_{0.6}\right) \mathrm{Cu}_{2} \mathrm{O}_{\mathrm{z}}$ samples.

경우 홀 농도와 상온 열기전력의 관계가 수식적으로 알려져 있다[17]. 그러므로 본 연구의 시편들은 홀 농도가 최적 상태에 비해 결핍한 상태이며,

$$
S=992 \exp (-38.1 p)
$$

의 관계식으로 부터 $\mathrm{CuO}_{2}$ 평면당 홀 농도는 $\mathrm{x}=0$, $0.25,0.5,0.75$ 및 1.0 일 때 각각 $0.088,0.085$, $0.081,0.078$, 및 0.075 개 이다. 이 결과는 홀농도의 차이가 최대 0.013 개 이며, $\mathrm{Nb}$ 치환에 따른 산소량의 변화는 매우 적음을 고려하고[9], $\mathrm{Nb}$ 의 가수가 +5 일 때 $\mathrm{Ru}$ 의 원자가가 4.74 이며, $\mathrm{Nb}$ 치환에 따른 홀이 모두 $\mathrm{CuO}_{2}$ 평면으로 이동했다면 설명된다. 실제 Awana 등[18]은 $\mathrm{Ru}-1222$ 계의 $\mathrm{Ru}$ 가수가 약 4.74임을 보고한 바 있다.

$\mathrm{Ru}-1222$ 계 초전도체의 경우 자기전이온도 및 자기모멘트가 발생되는 구조적 메카니즘에 대해 아직 일정 결론에 이르고 있지 못한 상태이다. 본 연구의 $\mathrm{Nb}$ 치환에 따른 임계온도의 변화는 $\mathrm{Ru}$ 에 의한 약한 강자성 성분은 이 계의 초전도 전이 온도에는 크게 영향을 미치지 않는 것을 보여 주었다. 그러나 $\mathrm{Nb}$ 치환량 $\mathrm{x}$ 가 0.5 이하인 경우 $\mathrm{Nb}$ 치환에 따른 약한 강자성모멘트가 급격히 감소함에도 불구하고 $\mathrm{ZFC}$ 자화도 측정결과는 반자성특성이 향상되지 못하고 오히려 감소하였다. 반면에 $\mathrm{x}=0.5$ 이상의 경우에

관측되는 반자성의 크기의 변화는 시편의 구성에서 $\mathrm{Ru}$ 량이 적을수록 반자성 특성이 향상되어 $\mathrm{Ru}$ 에 의한 자기모멘트가 시편 전체의 초전도 부피를 감소시키는 효과를 주는 것을 시사하고 있다. 그러므로 $\mathrm{Nb}$ 치환량 $\mathrm{x}$ 가 0.5 이상인 경우와 0.5 이하인 경우에 $\mathrm{Ru}$ 간의 상호작용에 어떤 차이가 있는 것으로 추정되며 국소구조의 변화를 추가적으로 연구할 필요가 있음을 시사한다.

\section{IV. 결 론}

$\left(\mathrm{Ru}_{1-\mathrm{x}} \mathrm{Nb}_{\mathrm{x}}\right) \mathrm{Sr}_{2}\left(\mathrm{Sm}_{1.4} \mathrm{Ce}_{0.6}\right) \mathrm{Cu}_{2} \mathrm{O}_{\mathrm{z}} \quad(\mathrm{x}=0$,

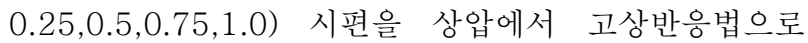
합성하여 $\mathrm{Nb}$ 치환에 따른 상형성, 초전도 및 자기적 특성에 대해 조사했다. $\mathrm{X}$-선 회절분석결과는 $\mathrm{Ru}$ 자리에 $\mathrm{Nb}$ 이 $100 \%$ 치환될 수 있음을 보여주었다. $\mathrm{Nb}$ 치환에 따른 자기적 특성 분석 결과는 $\mathrm{FC}$ 측정으로 관측되는 약한 강자성 특성은 $\mathrm{Nb}$ 치환량 $\mathrm{x}$ 가 처음 0.25 로 증가될 때 급격히 감소하며 그 이후의 증가에서는 상대적으로 완만한 감소를 보여주었다. 특히 저온부의 $\mathrm{FC}$ 측정곡선의 변곡점(inflection)을 이용해 결정된 임계온도는 $3 \mathrm{~K}$ 이내로 매우 적음을 보여주었다. 이 결과는 $\left(\mathrm{Ru}_{1-\mathrm{x}} \mathrm{Nb}_{\mathrm{x}}\right) \mathrm{Sr}_{2}\left(\mathrm{Gd}_{1.4} \mathrm{Ce}_{0.6}\right) \mathrm{Cu}_{2} \mathrm{O}_{\mathrm{z}}$ 및 $\left(\mathrm{Ru}_{1-\mathrm{x}} \mathrm{Nb}_{\mathrm{x}}\right) \mathrm{Sr}_{2}\left(\mathrm{Eu}_{1.5} \mathrm{Ce}_{0.5}\right) \mathrm{Cu}_{2} \mathrm{O}_{\mathrm{z}}$ 계의 임계온도 변화와 매우 유사하며, 이로서 $\mathrm{RuO}_{2}$ 층의 자기적 특성이 $\mathrm{CuO}_{2}$ 층의 초전도 전이온도특성에 미치는 효과는 매우 적음을 보여 주었다.

특히 $\mathrm{x}=0.5$ 이상의 경우 $\mathrm{ZFC}$ 측정으로 관측되는 반자성 특성과 $\mathrm{FC}$ 로 측정되는 마이스너효과가 모두 증가됨을 보여 주었으며 이는 $\mathrm{Nb}$ 치환량 $\mathrm{x}$ 가 0.5 이하인 시편의 경우 $\mathrm{Nb}$ 치환량이 증가될수록 $\mathrm{ZFC}$ 로 측정되는 반자성 특성이 감소되는 특성과 대비되며, $\mathrm{Nb}$ 치환량에 따라 초전도 부피가 크게 달라짐을 시사하며, 앞으로 그 국소구조 및 전자적 차이를 조사해볼 필요가 있다.

\section{ACKNOWLEDGEMENT}

본 연구는

지원 (2007313C00204, 받았다. X-선 회절 공동실험실습관의 장치가 이용되었다. 또한 SQUID 측정은 한국기초과학지원연구원에서 수행되었다.

\section{REFERENCES}

[1] E. B. Sonin and I. Felner, "Spontaneous vortex phase in a superconducting weak ferromaghet," Phys. Rev. B57, pp. R14000-R14003, 1998 and therein references.

[2] I. Felner, U. Asaf, Y. Levi and O. Millo, "Coexistence of magnetism and superconductivity in $\mathrm{R}_{1.4} \mathrm{Ce}_{0.6} \cdot \mathrm{RuSr}_{2} \mathrm{Cu}_{2} \mathrm{O}_{10-\delta}(\mathrm{R}$ = Eu and Gd)," Phys. Rev. B55, pp. R3374-R3377, 1997.

[3] C. Bernhard, J. L. Tallon, Ch. Niedermayer, Th. Blasius, A. Golnik, E. Brucher, R. K. Kremer, D. R. Noakes, C. E. Stronach and E. J. Ansaldo, "Coexistence of ferromagnetism and superconductivity in the hybrid ruthenate-cuprate compound $\mathrm{RuSr}_{2} \mathrm{GdCu}_{2} \mathrm{O}_{8}$ studied by muon spin rotation and $\mathrm{dc}$ magnetization," Phys. Rev. B59, pp.14099-14107, 1999.

[4] L. Bauernfeind, W.Widder and H. F. Braun, "Ruthenium-based 
layered cuprates $\mathrm{RuSr}_{2} \mathrm{LnCu}_{2} \mathrm{O}_{8}$ and $\mathrm{RuSr}_{2}\left(\mathrm{Ln}_{1+\mathrm{x}} \mathrm{Ce}_{1-\mathrm{x}}\right) \mathrm{Cu}_{2} \mathrm{O}_{10}$ $(\mathrm{Ln}=\mathrm{Sm}, \mathrm{Eu}$ and $\mathrm{Gd}), "$ Physica C, vol. 254, pp. 151-158, 1995.

[5] G.V.M. Williams and M.Ryan, "Raman transport and magnetization study of the $\mathrm{RuSr}_{2} \mathrm{R}_{2 \times} \mathrm{Ce}_{\mathrm{x}} \mathrm{Cu}_{2} \mathrm{O}_{10+\delta}(\mathrm{R}=\mathrm{Gd}$, Eu) high-temperature supercponducting cuprates," Phys. Rev. B64, pp. 094515(1)-094515(8), 2001.

[6] I. Felner and U. Asaf, "Superconductivity and weak ferromagnetism in $\mathrm{Eu}_{1.4} \mathrm{Ce}_{0.6} \mathrm{Ru}_{1-\mathrm{x}} \mathrm{Fe}_{\mathrm{x}} \mathrm{Sr}_{2} \mathrm{Cu}_{2} \mathrm{O}_{10-\delta}$, "Physica $\mathrm{C}$ vol. 292, pp. 97-103, 1997.

[7] V.P.S. Awana, H. Kishan, O. Eshkenazi, I. Felner, Rajeev Rawat, V. Ganesan and A. V. Narlikar, "Experimental study of magneto-superconductor $\mathrm{RuSr}_{2} \mathrm{Eu}_{1.5} \mathrm{Ce}_{0.5} \mathrm{Cu}_{2} \mathrm{O}_{10-\delta} \quad$ : peculiar effect of Co doping on complex magnetism and $\mathrm{T}_{\mathrm{c}}$ variation," $J$. Phys: Condens. Matter, vol. 19, pp. 026203(1)-026203(14), 2007.

[8] H. K .Lee and Y. C. Kim "Superconducting and magnetic properties of $\left(\mathrm{Ru}_{1-\mathrm{x}} \mathrm{Nb}_{\mathrm{x}}\right) \mathrm{Sr}_{2}\left(\mathrm{Eu}_{1.5} \mathrm{Ce}_{0.5}\right) \mathrm{Cu}_{2} \mathrm{O}_{\mathrm{z}}$ ", Int. J. Mod. Phys., vol. B17, pp. 3682-3687, 2003.

[9] H. K. Lee and G. V. M. Williams, "Effect of Nb doping on superconducting and magnetic properties of $\mathrm{RuSr}_{2}\left(\mathrm{Gd}_{1.5-\mathrm{y}} \mathrm{Eu}_{\mathrm{y}} \mathrm{Ce}_{0.5}\right) \mathrm{Cu}_{2} \mathrm{O}_{\mathrm{z}}$," Physica C, vol. 415, pp. 172-178, 2004.

[10] V.P.S. Awana, R. Lal, H. Kishan, A. V. Narlikar, M. Peurla and R.Laiho, "Experimental study of the magnetosuperconductor $\mathrm{RuSr}_{2} \mathrm{Eu}_{1.5} \mathrm{Ce}_{0.5} \mathrm{Cu}_{2} \mathrm{O}_{10-\delta}$ : Effect of Mo doping on magnetic behavior and $\mathrm{T}_{\mathrm{c}}$ variation", Phys. Rev. B73, pp. 014517(1)-014517(6), 2006
[11] N. Balchev, K. Nenkov, G. Mihova, B. Kunev and J. Pirov, "Superconducting and magnetic properties of Sn-doped Ru-1222”, Physica C. vol. 467, pp. 174-178, 2007.

[12] T.R.Yang, G. Ilonca, F. Beiusan, A.V. Pop, V. Toma, I. Matei and S. Patapis, "Synthesis of $\mathrm{Ru}_{1-\mathrm{x}} \mathrm{Sb}_{\mathrm{x}} \mathrm{Sr}_{2}\left(\mathrm{Eu}_{0.7} \mathrm{Ce}_{0.3}\right)_{2} \mathrm{Cu}_{2} \mathrm{O}_{10-8}$ and their magnetic and transport properties," Int. J. Mod. Phys., vol. B19, pp. 3511-3517, 2005.

[13] A. Ono, "Preparation of new superconducting cuprates $(\mathrm{Ru}, \mathrm{Nb}) \mathrm{Sr}_{2}(\mathrm{Sm}, \mathrm{Ce})_{2} \mathrm{Cu}_{2} \mathrm{O}_{z}$, 'Jpn. J. Appl. Phys., vol. 34, pp. L1121-L1122, 1995

[14] Watanabe, D.P.Hai, I.Kakeya and K. Kadowaki, "Physical properties and high-temperature phase analyses in magnetic high-Tc superconductor $\mathrm{RuSr}_{2} \mathrm{RE}_{2-\mathrm{x}} \mathrm{Ce}_{\mathrm{x}} \mathrm{Cu}_{2} \mathrm{O}_{10}$," Physica $\mathrm{B}$, vol. 359-361, pp. 433-435, 2005.

[15] H.K. Lee, "Superconductivity in the $(\mathrm{Pb}, \mathrm{V}) \mathrm{Sr}_{2}(\mathrm{Ca}, \mathrm{Tb}) \mathrm{Cu}_{2} \mathrm{O}_{z}$ system," J. Korean Phys. Soc., vol. 36, pp. 384-386, 2000.

[16] R. D. Shannon, "Revised Effective Radii and Systematic studies of interatomic distances in halides and chalcogenides," Acta Cryst., vol. A32, pp. 751-767, 1976.

[17] J. L. Tallon, C. Bernhard, H. Shaked, R. L. Hitterman and J. D. Jorgensen, "Generic superconducting phase behavior in high- $T_{c}$ cuprates: $T_{c}$ variation with hole concentration in $\mathrm{YBa}_{2} \mathrm{Cu}_{3} \mathrm{O}_{7-\delta}$ " Phys. Rev. B51, pp. 12911-12914, 1995.

[18] V.P.S. Awana, M. Karppinen, H. Yamauchi, M. Matvejeff. H.S.Liu and L.-Y. Jang, J. Low Temp. Phys., vol. 131, pp. 1211-1216, 2003. 